\title{
DINÂMICAS SOCIAIS, FAMILIARES E VULNERABILIDADES DE MULHERES PRIVADAS DE LIBERDADE
}

Maria Aparecida de Jesus X. Gusmão

Acadêmica de Enfermagem na Universidade do Estado de Mato Grosso, Câmpus de Tangará da Serra (MT), Brasil.

\section{Ana Cláudia Pereira Terças-Trettel}

Docente Adjunta do Curso de Enfermagem. UNEMAT - Tangará da Serra. Docente Permanente no Mestrado em Saúde Coletiva da Universidade Federal de Mato Grosso (UFMT), Brasil.

\section{Vagner Ferreira do Nascimento}

Docente Adjunto do Curso de Enfermagem. UNEMAT - Tangará da Serra, Brasil.

\section{Thalise Yuri Hattori}

Docente Adjunto do Curso de Enfermagem. UNEMAT - Tangará da Serra, Brasil.

\section{Luiz Eduardo Brescovit}

Docente FAEST-UNISSERRA, Brasil.

\section{Marina Atanaka}

Docente Permanente do Mestrado em Saúde Coletiva da Universidade Federal de Mato Grosso (UFMT) Brasil.

\section{Elba Regina Sampaio de Lemos}

Doutora em Medicina Tropical IOC/FIOCRUZ. Pesquisadora do Instituto Oswaldo Cruz, Rio de Janeiro, Brasil
RESUMO: O objetivo deste trabalho foi identificar as dinâmicas familiares, sociais e vulnerabilidades de mulheres privadas de liberdade. Estudo descritivo, exploratório e misto, realizado com 57 reeducandas de uma cadeia pública feminina de Mato Grosso. A coleta de dados foi realizada entre outubro de 2016 e outubro de 2017. A análise dos dados pautou-se no Modelo Calgary de Avaliação da Família. Entre as características familiares da estrutura interna e externa predominaram heterossexuais, com estrutura familiar coletiva, residiam com os familiares antes do aprisionamento e com seus filhos. O ciclo de vida familiar era caracterizado por adultos com crianças, e ordem de nascimento intermediária. Os limites da família foram descritos como flexíveis e a totalidade das reeducandas exercem papel passivo na estrutura familiar. Prevaleceu famílias extensas, com alguma crença religiosa, com destaque para relato de ambientes familiares harmoniosos. As características familiares desestruturadas foram identificadas como importante aspecto, que contribui para inserção da mulher no crime.

PALAVRAS-CHAVE: Características da Família; Mulheres; Prisões; Relações Familiares.

\section{SOCIAL AND FAMILY DYNAMICS AND VULNERABILITY OF INCARCERATED FEMALES}

ABSTRACT: Family and social dynamics and vulnerabilities of incarcerated females are analyzed. Current descriptive, exploratory and mixed study was undertaken with 57 incarcerated females in the female prison of Mato Grosso. Data were collected between October 2016 and October 2017. Data analysis was based on the Calgary Model of Family Evaluation. Among internal and external structure family characteristics, heterosexuals were predominant, with collective family structure, living with parents and with their children prior to incarceration. Family life cycle was characterized by adults with children and intermediate birth order. Family limits were described flexible and totality of incarcerated females have a passive role in family structure. Extensive families were dominant, with some religious beliefs, insisting on narratives of harmonious family environments. De-structured family characteristics were identified as an important aspect that pushes the female into crime.

KEY WORDS: Characteristics of the family; females; Prisons; Family relationships. 


\section{INTRODUÇão}

Historicamente o papel das mulheres na sociedade era pautado na execução das atividades maternas e conjugais. Essa imposição partia da premissa de que ela deveria se dedicar ao lar, educar os filhos e estar sob dominação do companheiro ${ }^{1}$. No decorrer dos anos, a mulher ascendeu seu papel participativo na sociedade, alcançando espaços que anteriormente eram ocupados prioritariamente por homens, o que proporcionou maior respeito, no entanto ainda vive uma situação desigual na perspectiva do gênero ${ }^{2}$.

Neste novo contexto, o contato com todas as adversidades que a vida impõe, em especial a desigualdade de gênero e seus enfrentamentos, aproximou as mulheres ao universo da criminalidade. No Brasil, os motivos que conduzem as mulheres para esse caminho são diversos, destacando-se os conflitos nas relações íntimo-afetivas, a falta de acesso à profissionalização e o desemprego ${ }^{3}$. Ainda destaca-se o envolvimento dessas mulheres com os traficantes, atitude esta que tem como propósito sustentar a dependência química e acabam por se relacionarem com parceiros que as conduz ao tráfico, situação de vida que mantêm com objetivo de suprir as necessidades econômicas da família que em sua maioria possuem estruturas e relações conflituosas, o que contribui sobremaneira para a ampliação de sua vulnerabilidade ${ }^{4,5}$.

$\mathrm{O}$ crescimento da população feminina infratora vem aumentando nos últimos anos. O número de mulheres privadas de liberdade no Brasil chegou a $37.380 \mathrm{em}$ 2014 e passando para $44.721 \mathrm{em}$ dois anos, o que deixou o país com a quinta maior população de mulheres encarceradas do mundo ${ }^{6}$.

O perfil da brasileira privada de liberdade pode ser geralmente descrito como jovem, solteira, com filhos, não branca, em situação prévia de vulnerabilidade, responsável pelo sustento familiar, com baixa escolaridade, oriundas de classes sociais economicamente desfavorecidas, exercendo atividades de trabalho informal em período anterior ao aprisionamento, com condenação direta ou indiretamente por tráfico de drogas ${ }^{5,7}$.

Após o encarceramento, as mulheres, diferentemente dos homens em situação de prisão, vivenciam em sua grande maioria o abandono familiar, seja dos parceiros, parentes próximos ou amigos ${ }^{4}$. O abandono familiar no período do aprisionamento está associado ao sofrimento, ao desamparo e à solidão, sendo visto como a se- gunda pena às mulheres ${ }^{4,8}$. Destaca-se ainda a dificuldade da família em perdoar as reeducandas, o que interfere diretamente na qualidade de vida e no seu processo de ressocialização $0^{8}$.

A família é vista como um sistema social de alicerce que transfere valores, crenças, ideias e significados que estão presentes na sociedade ${ }^{9}$. Quando a família se encontra em situação fragilizada ou desestruturada, ela se apresenta como fator importante que influencia no surgimento do comportamento delituoso do ser humano, pelo fato de ser a principal responsável pelo desenvolvimento do indivíduo e formação de seu caráter ${ }^{10}$.

A família tece redes que envolvem pessoas e relações próximas. Explicitar tais redes nos permite compreender o processo de desenvolvimento e organização familiar. Assim, o objetivo deste estudo foi identificar as dinâmicas familiares, sociais e vulnerabilidade de mulheres privadas da liberdade.

\section{MATERIAL E MÉTODO}

Trata-se de um estudo descritivo, exploratório e misto, realizado em uma cadeia pública feminina de um município da Região Médio Norte de Mato Grosso.

A amostra foi do tipo censitária em que fizeram parte do estudo todas as reeducandas desta instituição, tanto em prisão provisória como condenadas $(n=57)$. A coleta de dados ocorreu entre outubro de 2016 e outubro de 2017. Os instrumentos utilizados para coleta de dados foram a entrevista semiestruturada e as ferramentas qualitativas, preconizadas pelo Guia para Avaliação e Intervenção na Família ${ }^{13}$.

A coleta de dados foi iniciada através de reunião das pesquisadoras com todas as reeducandas, em que a pesquisa foi apresentada de forma coletiva, sanadas as dúvidas, assim aquelas que optaram por participar livremente realizaram a assinatura do Termo de Consentimento Livre e Esclarecido (TCLE). A entrevista foi realizada individualmente em ambiente reservado, de escolha da mulher, que poderia ser o consultório de enfermagem ou a sala de aula e teve duração em média de 45 minutos. Os pesquisadores que coletaram os dados foram enfermeiras que realizam pesquisa nesta instituição desde 2016. Após a construção do genograma e ecomapa o mesmo era apresentado à reeducanda para que a mesma confirmasse a exatidão das informações fornecidas no que cer- 
ne à estrutura e às relações descritas pelo entrevistador.

O genograma é um diagrama familiar que configura a estrutura intergeracional das relações familiares e o ecomapa, por sua vez, se refere a um diagrama da família em contato com outros grupos: pessoas, agências, instituições ${ }^{14}$. O genograma permite o detalhamento da estrutura familiar ao fornecer informações sobre os papéis de seus membros nas diferentes gerações, enquanto que o ecomapa foi utilizado com o objetivo de obter dados sobre os relacionamentos do indivíduo e/ou família com os demais sistemas/dispositivos sociais da comunidade.

Como recurso de sumarização dos dados, foram utilizadas as diretrizes da sociometria ${ }^{15}$, a fim de apresentar as principais características do círculo familiar e da rede social. A análise dos dados teve como parâmetros as orientações do Modelo Calgary de Avaliação da Família $(\mathrm{MCAF})^{13}$.

Adicionalmente, houve a análise individual de cada genograma e ecomapa, utilizando-se categoria e avaliação estrutural e as subcategorias da estrutura interna: composição familiar, gênero, subsistemas (subgrupos formados no interior do sistema familiar) e da estrutura externa: os sistemas mais amplos (instituições sociais, ambiente prisional e pessoas com as quais a família tem contato significativo). Estes dados foram sistematizados em planilhas eletrônicas e realizada a estatística descrita posteriormente no Statistical Package for the Social Sciences (SPSS), versão 20.0, apresentando os resultados constituídos de tabelas de frequência absoluta e relativa. Optou-se por ilustrar e descrever o genograma e ecomapa de dois indivíduos, estes que foram selecionados de forma aleatória simples.

O presente estudo seguiu todas as normas vigentes quanto aos aspectos éticos e foi aprovado pelo Comitê de Ética em Pesquisa com seres humanos da Universidade do Estado de Mato Grosso (CEP/UNEMAT), sob CAAE: 50417815.8.0000.5166 e Parecer $n^{0}$ 1.457.621/2016.

\section{RESULTADOS}

$O$ perfil predominante das participantes foi de pardas, com idade entre 18 a 31 anos, solteira, com até 4 filhos, ensino fundamental incompleto. A profissão de dona de casa prevaleceu entre as mulheres, sendo que o principal motivo da detenção foi o tráfico de drogas (artigo 33 do Código Penal) (Tabela 1).
Tabela 1. Aspectos sociodemográficos de reeducandas de uma cadeia pública feminina de Mato Grosso, Brasil, 2017. ( $\mathrm{N}=$ 57)

\begin{tabular}{|c|c|c|c|}
\hline \multicolumn{2}{|c|}{ Variáveis } & $\mathbf{N}$ & $\%$ \\
\hline \multirow{6}{*}{ Estado civil } & Solteira & 27 & $47,37 \%$ \\
\hline & Casada & 03 & $5,26 \%$ \\
\hline & União Estável & 15 & $26,32 \%$ \\
\hline & Separada/divorciada & 08 & $14,04 \%$ \\
\hline & Viúva & 03 & $5,26 \%$ \\
\hline & Outros & 01 & $1,75 \%$ \\
\hline \multirow{3}{*}{ Faixa etária } & 18-31 anos & 32 & $56,14 \%$ \\
\hline & $32-45$ anos & 18 & $31,58 \%$ \\
\hline & 46-59 anos & 07 & $12,28 \%$ \\
\hline \multirow{3}{*}{ Raça/cor } & Branca & 07 & $12,03 \%$ \\
\hline & Parda & 42 & $73,07 \%$ \\
\hline & Negra & 08 & $14,00 \%$ \\
\hline \multirow{4}{*}{ Escolaridade } & Não Alfabetizado & 01 & $1,75 \%$ \\
\hline & $\begin{array}{l}\text { Ensino Fundamental } \\
\text { (completo ou incom- } \\
\text { pleto) }\end{array}$ & 32 & $56,14 \%$ \\
\hline & $\begin{array}{l}\text { Ensino Médio (comple- } \\
\text { to ou incompleto) }\end{array}$ & 22 & $38,60 \%$ \\
\hline & $\begin{array}{l}\text { Ensino Superior (com- } \\
\text { pleto ou incompleto) }\end{array}$ & 02 & $3,51 \%$ \\
\hline
\end{tabular}

As características familiares analisadas permearam os aspectos da estrutura familiar interna e externa. $\mathrm{Na}$ estrutura interna, observou-se a composição familiar (estrutura, residir com a família antes da detenção, ter filhos e fase do ciclo de vida da família), orientação sexual, ordem de nascimento, limites e subsistemas. Na estrutura externa, observou-se família extensa, sistemas mais amplos, religião e ambiente.

$\mathrm{Na}$ Tabela 2 é possível observar que as reeducandas em sua maioria eram heterossexuais $(78,95 \%)$, com estrutura familiar coletiva $(84,21 \%)$, residiam com seus familiares antes do aprisionamento $(77,19 \%)$, com seus filhos (82,46\%). O ciclo de vida da família era formado por adultos com crianças $(36,84 \%)$ e a ordem do nascimento era intermediária (42,11\%). Os limites da família foram descritos como flexível $(64,91 \%)$ e a totalidade de mulheres exerce um papel passivo na estrutura familiar. 
Tabela 2. Características familiares de reeducandas de uma cadeia pública feminina de Mato Grosso, Brasil, 2017. ( $N=57)$

\begin{tabular}{|c|c|c|c|c|c|}
\hline \multicolumn{4}{|c|}{ Variáveis } & $\mathrm{N}$ & $\%$ \\
\hline \multirow{21}{*}{$\begin{array}{l}\text { Estrutura } \\
\text { interna }\end{array}$} & \multirow{10}{*}{ Composição familiar } & \multirow{2}{*}{ Estrutura } & \multirow{2}{*}{$\begin{array}{l}\text { Individual } \\
\text { Coletiva }\end{array}$} & 09 & $15,79 \%$ \\
\hline & & & & 48 & $84,21 \%$ \\
\hline & & \multirow{2}{*}{$\begin{array}{l}\text { Moravam juntos com } \\
\text { família antes da de- } \\
\text { tenção }\end{array}$} & Sim & 44 & $77,19 \%$ \\
\hline & & & Não & 13 & $22,81 \%$ \\
\hline & & Tem filhos & Sim & 47 & $82,46 \%$ \\
\hline & & & Não & 10 & $17,54 \%$ \\
\hline & & & Adultos com crianças & 21 & $36,84 \%$ \\
\hline & & & Adultos com criança e adolescentes & 16 & $28,07 \%$ \\
\hline & & (5) & Só adultos & 17 & $29,83 \%$ \\
\hline & & & Adultos com idoso & 03 & $5,26 \%$ \\
\hline & \multirow{3}{*}{$\begin{array}{l}\text { Orientação sexual } \\
\text { da reeducanda }\end{array}$} & \multirow{3}{*}{\multicolumn{2}{|c|}{$\begin{array}{l}\text { Heterossexual } \\
\text { Homossexual } \\
\text { Não informado } \\
\end{array}$}} & 45 & $78,95 \%$ \\
\hline & & & & 09 & $15,79 \%$ \\
\hline & & & & 03 & $5,26 \%$ \\
\hline & \multirow{5}{*}{$\begin{array}{l}\text { Ordem de nasci- } \\
\text { mento }\end{array}$} & \multicolumn{2}{|l|}{ Unigênito } & 06 & $10,53 \%$ \\
\hline & & \multicolumn{2}{|l|}{ Primogênito } & 12 & $21,05 \%$ \\
\hline & & \multicolumn{2}{|l|}{ Intermediário } & 24 & $42,11 \%$ \\
\hline & & \multicolumn{2}{|l|}{ Últimogênito } & 11 & $19,30 \%$ \\
\hline & & \multicolumn{2}{|l|}{ Não informado } & 04 & $7,01 \%$ \\
\hline & \multirow[t]{2}{*}{ Limites } & \multirow{2}{*}{\multicolumn{2}{|c|}{$\begin{array}{l}\text { Rígido } \\
\text { Flexível }\end{array}$}} & 20 & $35,09 \%$ \\
\hline & & & & 37 & $64,91 \%$ \\
\hline & Subsistemas & \multicolumn{2}{|l|}{ Passivo } & 57 & $100 \%$ \\
\hline \multirow{16}{*}{$\begin{array}{l}\text { Estrutura } \\
\text { externa }\end{array}$} & \multirow{2}{*}{ Família extensa } & Sim & & 35 & $61,40 \%$ \\
\hline & & Não & & 22 & $38,60 \%$ \\
\hline & Sistemas mais am- & Conflitos entre reeduc & andas & 20 & $35,09 \%$ \\
\hline & & & 37 & $64,91 \%$ & \\
\hline & Docui Dliniz̃ & Sim & & 46 & $80,70 \%$ \\
\hline & 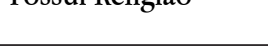 & Não & & 11 & $12,30 \%$ \\
\hline & & & Ambiente Familiar & & \\
\hline & & Harmonioso & & 36 & $63,16 \%$ \\
\hline & & Distante & & 14 & $24,56 \%$ \\
\hline & & Não informado & & 07 & $12,28 \%$ \\
\hline & & & Ambiente Prisional & & \\
\hline & Ambiente & Harmonioso & & 11 & $19,30 \%$ \\
\hline & & Conflituoso & & 06 & $10,53 \%$ \\
\hline & & Não informado & & 40 & $70,17 \%$ \\
\hline & & Recebe visitas & Sim & 26 & $45,61 \%$ \\
\hline & & Não & 31 & $54,39 \%$ & \\
\hline
\end{tabular}


A estrutura externa demonstra importante influência do cárcere na estrutura familiar. As mulheres descrevem o predomínio de famílias extensas (61,40\%), pois consideram tanto a família genética como as pessoas que convivem no cárcere como integrantes do círculo familiar. A religião também é apontada pela maioria dessas mulheres $(80,70 \%)$. Em relação ao ambiente familiar de origem, é destacada a harmonia familiar (63,16\%). Já o ambiente prisional apresenta conflitos. No entanto, $70,17 \%$ das mulheres não expressaram suas concepções sobre o tipo de ambiente com o restante da comunidade prisional que inclui os profissionais de segurança, o que leva a reflexão de que a relação do poder ali existente pode ter influenciado para que essa informação fosse omitida e permanecesse velada.
Por amostragem aleatória simples foram sorteadas as reeducandas M53 e M18 para ilustração do genograma e ecomapa e, conforme Figura 1, a reeducanda M53, 19 anos, parda, com ensino fundamental incompleto, uso indiscriminado de álcool e outras drogas por seus pais durante a infância, crescendo em abrigo para menores. Relata relação conflituosa com a mãe, usuária de drogas e que buscou no casamento um refúgio, porém seu ex-marido tinha muito ciúme, motivo de muitas brigas e violência doméstica. Atualmente, o mesmo está detido por roubo. Antes de ser presa vivia com o filho de dois anos. Este, no momento, se encontra em um abrigo para menores. Relata sentir muita saudade do filho e da avó que considera como mãe, e que a ausência de visitas de ambos é sua maior punição.Em relação ao relacionamento com as demais reeducandas, diz ser distante e indiferente por conta das fofocas e brigas, porém estabeleceu forte relação de amizade com três delas.

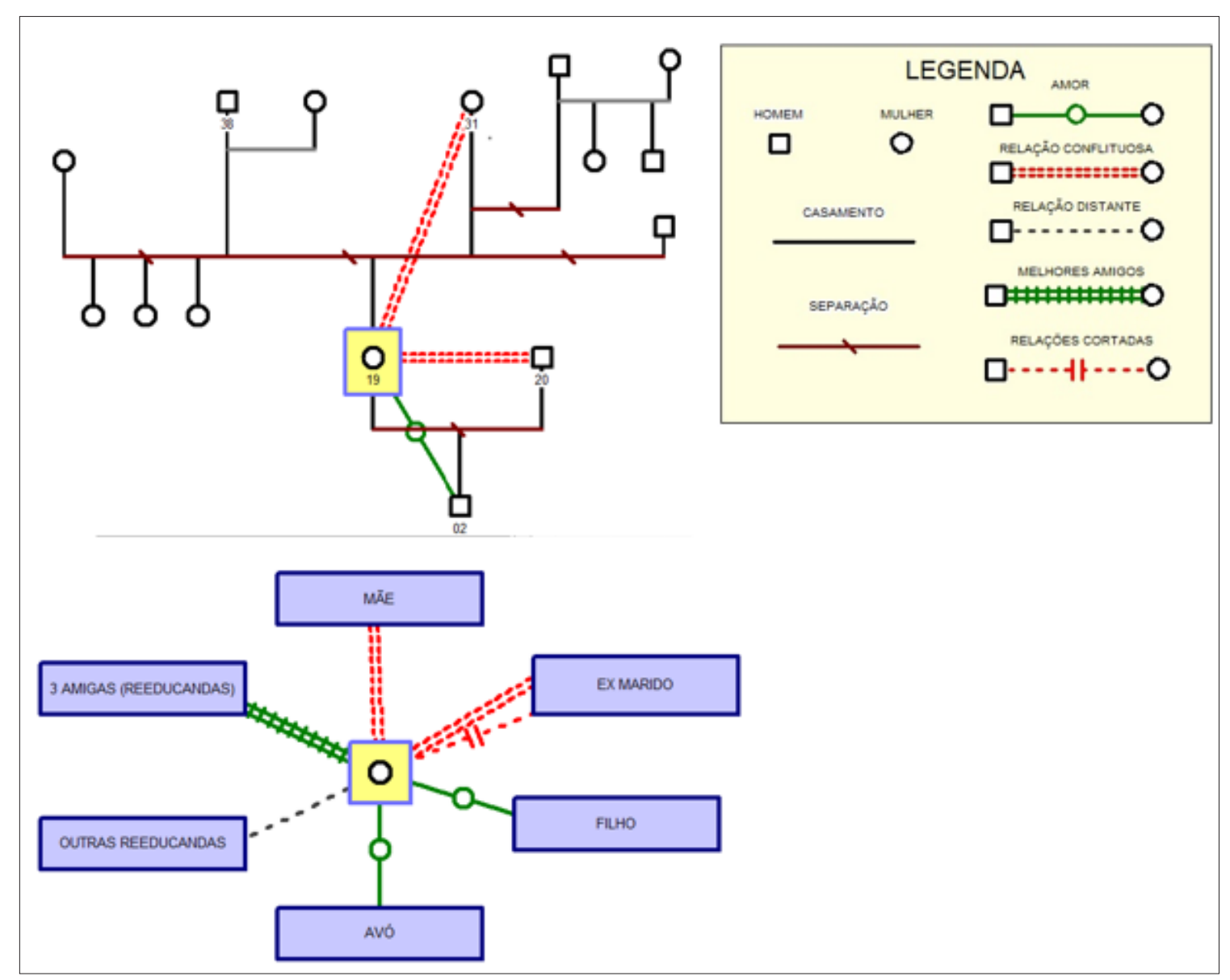

Figura 1. Genograma e ecomapa da reeducanda 53, cadeia pública feminina de Mato Grosso, Brasil, 2017. 
Reeducanda M18, 21 anos, parda, com ensino fundamental incompleto e detida por tráfico de drogas. Refere que cresceu em um ambiente violento no qual os pais faziam uso indiscriminado de álcool e outras drogas e a violência doméstica e familiar eram rotinas. Cortou relações com seu pai biológico, antes mesmo da separação com a mãe. Já com a mãe e o padrasto, a relação é distante em decorrência de brigas e agressões. Antes da detenção residia com os dois filhos, que nesse momento estão sob cuidados de uma tia próxima. Tem uma relação conflituosa com o ex-marido e pai dos filhos. Dentro do ambiente prisional tem ligação hostil com os agentes de segurança penitenciária, e grande conflito com outra reeducanda que divide a cela. Relata ter ligação harmoniosa e forte com quatro reeducandas.

\section{DISCUSSÃO}

A análise dos aspectos sociodemográficos apresentados também encontrou informações semelhantes a de outros estudos, com a população caracterizada por serem jovens, pardas, com baixa escolaridade, solteiras e com filhos ${ }^{16,17,18}$. Esse perfil é decisivo para a análise das características familiares, uma vez que são condicionantes para o acesso ao mundo do crime e ampliação da vulnerabilidade a que estiveram e estão expostas.

O encarceramento amplia as vulnerabilidades dessa mulher, seja no âmbito pessoal ou familiar, este último que apresenta como destaque a perda da autoridade da mãe sobre os filhos, assim como a falta de identificação em decorrência do afastamento ${ }^{19}$. O mesmo autor destaca que as vulnerabilidades de mulheres encarceradas são anteriores à detenção pelo baixo nível social e econômico, dificuldade de acesso a informações de todas as ordens e fragilidades nas relações familiares, estes que após a detenção são extremamente maiores ${ }^{19}$.

Em sua pesquisa, Silva ${ }^{9}$ aborda o impacto destrutivo que o encarceramento feminino causa diretamente na vida da família, já que a situação em que se encontram traz dúvidas quanto ao destino dos filhos, uma vez que a mulher é vista como a principal responsável por estes e em sua grande maioria responsável por toda a família.

Tal realidade traz a reflexão de que o rompimen- to do vínculo familiar dessas mulheres implica em algo doloroso, principalmente em relação aos filhos que ao se sentirem abandonados pela figura materna se desestruturam e ficam mais vulneráveis à marginalização?

Quanto aos limites, o MCAF retrata que os mesmos definem quem e como participam da família, ao serem descritos como flexíveis revelam que outras pessoas foram incluídas no sistema familiar, agora fragilizado devido ao distanciamento imposto pela detenção. Segundo Mirabete $^{20}$, os laços mantidos principalmente com a família são essencialmente benéficos para o apenado, porque o levam a sentir que, mantendo contatos, embora com limitações, com pessoas que se encontram fora do presídio, não foi excluído da comunidade. Ao se distanciar da família biológica, as mulheres privadas de liberdade em geral buscam suprir necessidades familiares rompidas/ distanciadas em indivíduos que agora fazem parte de sua nova realidade.

O encarceramento priva o indivíduo de desempenhar seus papéis sociais que realizava em seu cotidiano anterior à detenção, assim após adentrar o sistema prisional podem se tornar passivos nas relações familiares. A frequência de visitas (amigos, cônjuges, filhos e demais familiares) é extremamente baixa pois diversos são os fatores que contribuem para isso como, por exemplo, os dias e horários de visita incompatíveis com a disponibilidade familiar; a manutenção da prática de revistas, em que a privacidade de seu corpo é destituída; o ambiente degradante para receber visitação dos filhos e familiares ${ }^{21}$.

Em relação à estrutura externa, a reeducanda passa por um processo de profunda desestruturação emocional e a ligação religiosa nessa condição oferece a possibilidade de reflexão acerca do crime perpetrado e alicerce para uma nova vida. A doutrina cristã em especial auxilia no resgate da autoestima da reeducanda, ao dizer que os pecados através da confissão diante de Deus e o arrependimento poderão ser perdoados ${ }^{22}$. Essa ideia de perdão traz consigo a apresentação de uma nova perspectiva de futuro para a mulher ${ }^{21}$. Essa experiência religiosa reestabelece o sentido da existência, ensinando questões essenciais ao convívio em sociedade, como a importância de se amar o próximo, de se ter humildade e de ser solidário ${ }^{22}$.

Ao abordar a orientação sexual grande parte das 
reeducandas apontou a heterossexualidade, porém por estarem privadas do ambiente social, as mesmas não se encontram vinculadas a um relacionamento afetivo com homens. E ao vivenciarem esse abandono afetivo, algumas delas por estarem longe de seus parceiros e pela impossibilidade de terem acesso a outros homens para estabelecerem novas relações, desenvolvem um comportamento homossexual situacional, também conhecido como de circunstância, ocasional, adquirido, facultativo ou ainda pseudo-homossexualidade, na qual, dependendo da situação leva o indivíduo a alcançar objetivos diferentes à sua orientação sexual habitual, tais como ganhos, proteção, conservação de uma relação, dominação, submissão entre outros, os quais podem ser ignorados ou não, quando o meio muda ${ }^{23}$. Fato este não observado nos genogramas ilustrados nesse manuscrito, pois estes foram selecionados por sorteio aleatório simples, porém presente nesta realidade.

Todos os comportamentos do indivíduo vão se desenvolvendo de acordo com referências e vivências familiares, assim a família de origem tem um papel fundamental no desenvolvimento humano, pois é o principal agente de conexão entre o indivíduo e a sociedade, constitui-se um lugar para a aquisição de limites, conexões, ética, respeito que o auxiliará na vivência de relações afetivas profundas ${ }^{24}$. Assim, as crianças vão sendo progressivamente inseridas com o meio externo, cada vez mais ampliado, e também está relacionado à importância emocional das figuras parentais ${ }^{25}$. Esse distanciamento físico e temporal dos pais durante a infância e adolescência é entendido como uma oportunidade de desenvolvimento e exploração, que posteriormente permite o processo de individualização no seio das suas relações, quer com os pais, pares amigos ou sociedade ${ }^{18,24,25}$.

$\mathrm{O}$ estudo elaborado por Dutra ${ }^{10}$ descreve que o contexto familiar em certos casos pode ser o fator gerador e propulsor para que o sujeito desenvolva comportamentos delituosos. Somado a isso, o mesmo autor aponta que a maioria das mulheres reclusas no sistema prisional traz consigo um histórico de violência sofrida em seu próprio meio familiar, resultando em uma sequência de acontecimentos que traçam a trajetória da população feminina encarcerada, o que contrapóe os achados de ambiente familiar harmonioso.
Além do ciclo de violências vividas no meio familiar antes da detenção, Ely, Cechinel e Camargo ${ }^{26} \mathrm{em}$ seu estudo revelam que, dentro do sistema prisional, a mulher sofre ainda discriminação e preconceito, carregando consigo vários estereótipos por sua condição carcerária, configurando uma forma de violência velada, na qual as mesmas possivelmente nem percebam e aceitam ameaças, intimidações, pressão psicológica como parte de seu cotidiano, já que não podem mudar tal realidade. Corroborando com o estudo, Humberlino ${ }^{27}$ retrata que estas violências diversas vezes são imperceptíveis porque a maioria das mulheres reclusas não reconhece os maus tratos como um tipo de violência, e pela condição que se encontram acreditam que devam obedecer ao que é imposto pela instituição tornando algo natural.

As características apresentadas demonstram que o aprisionamento pode ser, talvez, resultado do desequilíbrio familiar, já que a família é compreendida como alicerce na construção do caráter como ser humano. Ao analisar os genogramas e ecomapas apresentados previamente neste manuscrito, percebe-se nitidamente uma desestruturação no desenho familiar, apontado por situações de conflito e rompimento de ligações entre os membros, favorecidas por situações de violências vivenciadas desde a infância. Como solução para os problemas enfrentados no meio familiar surge o envolvimento amoroso, que estabelece, neste caso, novas situações de violência que resultam em um ciclo de separações e conflitos familiares passados para as próximas gerações ${ }^{24,25}$. Sendo assim, a desestruturação familiar favorece negativamente a fragilização do indivíduo, deixando-o em uma posição de vulnerabilidade, expondo a situações de exclusão social e violência.

Outra estratégia importante a destacar é a necessidade de ações informativas e/ou educativas nos ambientes prisionais como abordam Corsino et al. ${ }^{28}$; as mulheres verbalizaram livremente a necessidade de acesso a ações de informação. Neste sentido sugere-se que a abordagem de informação e educação em saúde seja ampliada tanto para essas mulheres como suas famílias a fim de reduzir as fragilidades geradas pelo distanciamento familiar após o cárcere. 


\section{CONSIDERAÇÕES FINAIS}

É possível afirmar que o afastamento dos vínculos e a ruptura da dinâmica familiar resultam das fragilidades sociais e iniquidades que estão sujeitas essas mulheres e suas famílias. Aquelas sem as mínimas condições econômicas são expostas a situações de vulnerabilidades sociais que fragilizam suas funções protetivas e, consequentemente, o convívio familiar. Portanto, a falta de um desenho familiar mais sólido e que propicie a seus membros o suporte necessário para seu desenvolvimento gera rupturas, desvinculação e empobrecimento das relações humanas.

As mulheres deste estudo, ao serem aprisionadas, vivenciaram uma realidade de segregação social, com danos significativos para sua saúde física e mental, pois houve perda/bloqueio de laços afetivos, privação da liberdade, sofrimento pelo afastamento familiar, prejuízos sexuais e aumento das formas de violência.

Muitas mulheres antes da reclusão eram responsáveis pela família e com o encarceramento levou à desorganização familiar. É necessário reconhecer que o abandono familiar interfere na qualidade de vida, prejudicando o processo de ressocialização. Na busca pela sobrevivência, adaptação e superação do cárcere, tentam buscar entendimento apegando a fé em Deus, no apoio de outras companheiras de cárcere e na esperança da liberdade.

É importante considerar algumas limitações do estudo, nomeadamente a transversalidade que o caracteriza, bem como o número da amostra e a impossibilidade de ser ampliado a todas as mulheres em situação de prisão. No entanto, destaca-se contribuir para ampliação do conhecimento sobre a importância da família nas relações humanas e seu impacto na vida das reeducandas, seja anterior ou posterior ao seu cárcere.

\section{REFERÊNCIAS}

1. Lobato A, Nascimento ED, Silva GLS, Cirne EA, Santos APFS. Mulheres criminosas: analisando a relação entre a desestruturação familiar e criminalidade. Paraíba (PB). In: Anais do XV ENABRAPSO. [internet] 2009 Mai 01-Ago 17 [acesso em 2018 Abr 23]; p. 10.
Disponível em: http://www.abrapso.org.br/siteprincipal/images/Anais_XVENABRAPSO/242.\%20mulheres\%20criminosas.pdf.

2. Faria LRU de. A população carcerária feminina relacionada aos crimes econômicos lucrativos e não lucrativos [monografia] Graduação em Economia. Rio Grande do Sul: LUME, Repositório Digital da Universidade Federal do Rio Grande do Sul. [internet] 2010 [acesso em 2018 Abr 23]; 72p. Disponível em: http://hdl.handle.net/10183/29468.

3. Santos EL, Simon BS, Schimitd SMS, Machado BP. J. nurs. health [internet] 2016 [acesso em 2018 Nov 15]; 6 (1): 4-16. Disponível em: http://pesquisa.bvsalud.org/brasil/resource/pt/bde-31712.

4. Mignon S. Questões de saúde de mulheres encarceradas nos Estados Unidos. Cien Saude Colet. [internet] 2016 [acesso em 2018 Abr 23]; 21 (7): 2051-2060. Disponível em: http://www. scielo.br/scielo.php?script $=$ sci_arttext\&pi$\mathrm{d}=$ S1413-81232016000702051\&lng $=$ en\&nrm $=\mathrm{i}$ so.

5. Matos R, Machado Carla. Criminalidade feminina e construção do género: Emergência e consolidação das perspectivas feministas na Criminologia. Aná. Psicológica, Lisboa, [internet] 2012 [acesso em 2018 Nov 15]; 30 (1-2). Disponível em: http:/ www.scielo.mec.pt/scielo.php?script $=$ sci_arttext\&pid $=S 0870=82312012000100005-\& \operatorname{lng}=$ pt\&nrmiso.

6. Ministério da Justiça (BR). Infopen Mulheres - Levantamento Nacional de Informações Penitenciárias 2014. Depen - Departamento Penitenciário Nacional. [internet] 2015 [acesso em 2018 Abr 26]. Disponível em: http://www.justiça.gov.br/noticias/estudo-traca-perfil-da-populacao-penitenciaria-feminina-no-brasil/relatorio-infopen-mulheres.pdf.

7. Cassol PD, Silva MBO, Dinarte PV. A vida mera das obscuras: sobre a vitimização e a criminalização da mulher Rev. Direito Práx. [internet] 2018 [acesso em 2018 Nov 15]; 9 (2): 810-831. DOI: 10.1590/2179- 
$8966 / 2017 / 25503$

8. Jesus ACF de, Oliveira LVO, Oliveira EA, Brandão GCG, Costa GMC. O significado e a vivência do abandono familiar para presidiárias, Rev Ciencia e Saude. [internet] 2015 [acesso em: 2018 Abr 26]; 8 (1): 1925. Disponível em: http://revistaseletronicas.pucrs. br/ojs/index.php/faenfi/about/.

9. Diniz D, Paiva J. Mulheres e prisão no Distrito Federal: itinerário carcerário e precariedade da vida. Rev Bras de Ciências Criminais. [internet] 2014 [acesso em 2018 Nov 15]; 111: 313-328. Disponível em: https://dialnet.unirioja.es/servlet/articulo?codigo $=5024572$.

10. Cortina MOC. Mulheres e tráfico de drogas: aprisionamento e criminologia feminista. Rev. Estud. Fem. [internet] 2015 [acesso em 2018 Nov 15]; 23 (3): 761-778. Disponível em: http:// www.scielo.br/scielo.php?script $=$ sci_arttext\&pi$\mathrm{d}=$ S0104-026X2015000300761\&lng $=$ en\&nrm $=\mathrm{i}$ so

11. Cerveny CMO. A família como modelo: desconstruindo a patologia. 2. ed. São Paulo: Livro Pleno, 2011. 158p.

12. Cecilio HPM, Santos KS, Marcon SS. Modelo Calgary de Avaliação da Família: experiência em um projeto de extensão. Cogitare Enferm. [internet] Set 2014 [acesso em 2018 Mai 02]; 19 (3): 536-544. Disponível em: https://revistas.ufpr.br/cogitare/article/viewFile/32729/23239.

13. Wright LM, Leahey M. Enfermeiras e famílias: um guia para avaliação e intervenção na família. $5^{\mathrm{a}} \mathrm{ed}$. São Paulo: Medsi; 2012. 365p.

14. Nascimento LC, Dantas IRO, Andrade RD, Mello DF de. Genograma e ecomapa: contribuições da enfermagem brasileira. Texto Contexto Enferm. [internet] 2014 Jan-Mar [acesso em 2018 Mai 04]; 23 (1): 211220. Disponível em: http://www.scielo.br/pdf/tce/ v23n1/pt_0104-0707-tce-23-01-00211.pdf.

15. Moreno JL. Quem Sobreviverá? Fundamentos da
Sociometria, Psicoterapia de Grupo e Sociodrama. Goiânia: Dimensão Editora; 1992. 450p.

16. Graça BC da, Mariano MM, Silva JH da, Nascimento VF, Hattori TY, Terças ACP. Perfil sociodemográfico e prisional das detentas de um município do médio norte de Mato Grosso. Semina Ciênc Biol Saude. 2018; 39 (3). No prelo.

17. Macedo FRM, Terra FS, Santos SVM, Miranda RPR, Santana APA, Pereira AS. Perfil Socioeconômico e saúde ginecológica de presidiárias. SANARE. [internet] 2016 [acesso em 2018 Mai 19]; 15 (2): 30-36. Disponível em: https://sanare.emnuvens.com.br/sanare/article/viewFile/1035/581.

18. Pereira ÉL. Famílias de mulheres presas, promoção da saúde e acesso às políticas sociais no Distrito Federal, Brasil. Cien Saude Colet. [internet] 2016 [acesso em 2018 Mai 19]; 21 (7): 2123-2134. $=$ S1413-81232016000702123\&lng $=e n \& n r m=i$. so\&tlng $=\mathrm{pt}$

19. Silva $\mathrm{AD}$. Mãe/mulher atrás das grades: a realidade imposta pelo cárcere à família monoparental feminina [online]. São Paulo: Editora UNESP; São Paulo: Cultura Acadêmica, 2015, 224p. Disponível em: http://books.scielo.org/id/vjtsp/pdf/silva-9788579837036.pdf

20. Mirabete JF. Execução Penal: comentários a lei $\mathrm{N}^{\circ}$ 7.210, de 11-7-1984. 12 ed. São Paulo: Atlas; [internet] 2014 [acesso em 2018 Mai 20]; 1072. Disponível em: http://www.lexml.gov.br/urn/urn:lex:br:rede.virtual.bibliotecas:livro:2006;000779430.

21. Jesus ACF, Oliveira LV, Oliveira EA, Brandão GCG, Costa GMC. O significado e a vivência do abandono familiar para presidiárias. Ciência \& Saúde [internet] 2015 [acesso em 2018 Nov 15]; 8 (1): 19-25. Disponível em: http://revistaseletronicas.pucrs.br/ojs/ index.php/faenfi/article/viewFile/19535/13139

22. Dias MFM. A influência da religião na ressocialização do cidadão preso [monografia] Graduação em Direito. Caruaru: Centro Universitário Tabosa de Almeida Asces - UNITA; [internet] 2017 [acesso em 2018 Mai 
21]; 59p. Disponível em: http://repositorio.asces. edu.br/handle/123456789/921.

23. Francisco RS. Homossexualidade feminina no cárRecebido em: 13/08/2018 cere: estratégias e (re) configurações de gênero Aceito em: 28/12/2018 como forma de sobrevivência. Vértices. [internet] 2015 [acesso em 2018 Mai 22]; 17 (1): 7-21. Disponivel em: https://www.researchgate.net/ publication/282208011_Female_homosexuality_ the_case_of_the_Carlos_Tinoco_da_Fonseca_female_prison_in_Campos_dos_Goytacazes_RJ.

24. Correia F, Mota C. Papel do ambiente familiar no desenvolvimento de sintomatologia psicopatológica em jovens adultos. Psicologia Clinica. [internet] 2017 [acesso em 2018 Mai 22]; 29 (2): 253-271. Disponível em: http://pepsic.bvsalud.org/scielo.php?script $=$ sci_arttext\&pid $=$ S0103-

25. Bronfenbrenner, U. Bioecologia do desenvolvimento humano: tornando os seres humanos mais humanos. Porto Alegre: Artmed, 2011.

26. Priori C. A construção social da identidade de gênero e as mulheres na prisão. Rev NUPEM [Internet]. 2012 [acesso em 2018 Nov 15]; 3 (4): 191-0. Disponível em: http://www.fecilcam.br/revista/index.php/ nupem/article/viewFile/89/64

27. Oliveira LV, Costa GMC, Medeiros KKAS, Cavalcanti AL. Epidemiological profile of female detainees in the Brazilian state of Paraíba: a descriptive study. Online Braz J Nurs [Internet]. 2013 [acesso em 2018 Nov 15]; 12 (4): 892-901. Disponível em: http:// www.objnursing. uff.br/index.php/nursing/article/ view/4284

28. Corsino PKD, Nascimento V, Lucieto GC, Hattori TY, Graça BC, Espinosa MM e Terças-Trettel ACP. Eficácia de ação educativa com reeducandas de cadeia pública de Mato Grosso sobre o vírus HPV. Revista Saúde e Pesquisa [internet] 201811 (1): 115-126. [acesso em: 2018 Jun 22]. Disponível em: http://periodicos.unicesumar.edu.br/index.php/saudpesq/article/ view/6372/3160. 